\title{
PULMONARY STENOSIS PRODUCED BY ANEURYSM OF THE ASCENDING AORTA
}

\author{
BY \\ KARL L. DICKENS \\ From the School of Medicine, Louisiana State University, and Charity Hospital of \\ Louisiana at New Orleans \\ Received April 24, 1940
}

Although aneurysm of the aorta is not itself uncommon, its location so that pulmonary stenosis and insufficiency result and so that the symptoms and signs simulate those of aneurysm of the pulmonary artery justifies a report and brief discussion.

\section{Case Report}

A negro woman, 28 years of age, was first admitted to Charity Hospital of Louisiana at New Orleans in May 1938, complaining of shortness of breath, which had been present for two weeks. A month before, an attack of what she termed "indigestion" had been followed by severe diarrhœa with considerable tenesmus and the passage of pure blood; the diarrhœa disappeared within a week and she felt fairly well for two weeks. Then she had a sudden, severe stabbing pain in the left chest, radiating to the left shoulder. She was dyspnœic and restless. The pain continued, at first with remissions, until she entered the hospital. The past history contained no relevant facts.

Physical examination revealed a fairly well developed and well nourished woman who appeared acutely ill and was dyspnœic even on a high back rest. The pulse rate was 90 per minute, the respiratory rate 20 , and the blood pressure $95 / 40$. The skin and mucous membranes appeared slightly pale.

The chief physical findings were confined to the chest. There was slight fullness in the anterior thoracic wall in the third interspace, pressure over which elicited some pain. Expansion was equal on both sides, and resonance and breath sounds were normal. The apex beat of the heart was best seen and felt in the fifth interspace, slightly outside the mid-clavicular line. Percussion revealed the heart to be slightly enlarged to the left. There was a systolic thrill over the præcordium, and a continuous murmur with systolic accentuation, heard most clearly over the area of the pulmonary valve but also audible over the entire præcordium, and replacing the second pulmonary sound. The arteries felt normal and the pulse, although of slightly low tension, was otherwise normal and not of the Corrigan type.

The abdomen was somewhat distended, but was otherwise normal. Pelvic examination revealed old inflammatory disease and rectal examination showed external hæmorrhoids and lymphogranulomatous obstruction an inch from the 
anal opening. The extremities were normal, and the reflexes were normal and equal on both sides. The urine was normal and the blood Wassermann reaction was strongly positive.

At this time, as on all subsequent admissions, the radiologist reported an aneurysm of the pulmonary artery (Figs. 1-2), the measurements of which were

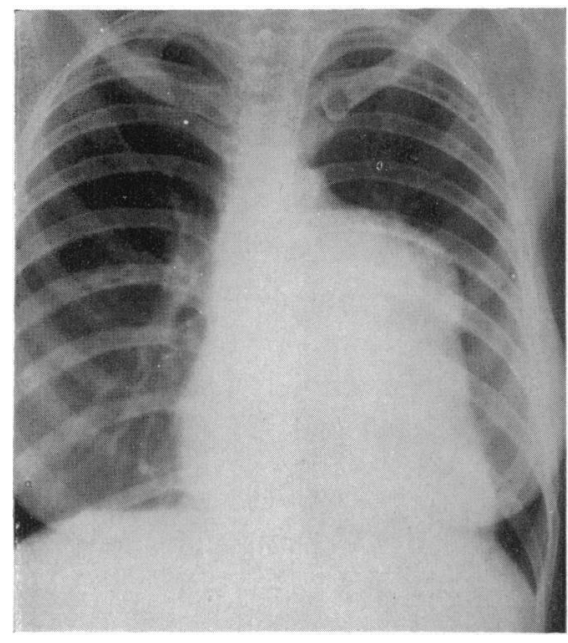

A

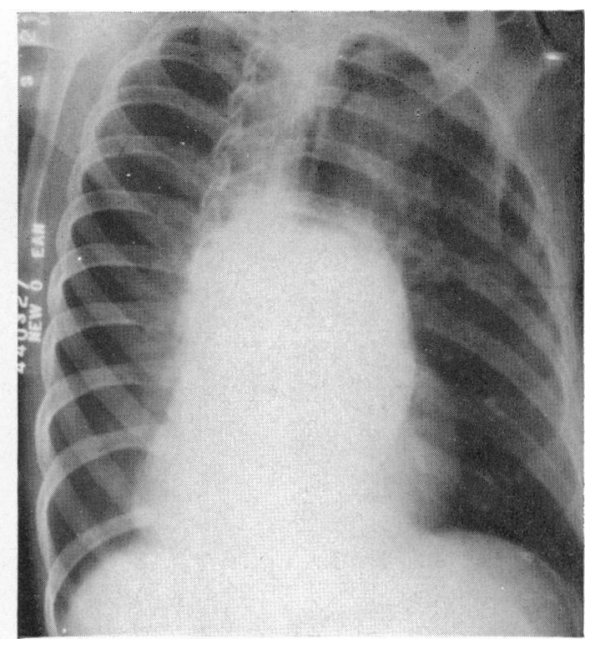

B

FIG. 1.-(A) Radiogram of chest, showing a normal aortic knob and enlargement in the region of the pulmonary conus and artery.

(B) First oblique position, showing the aneurysm of the ascending aorta.

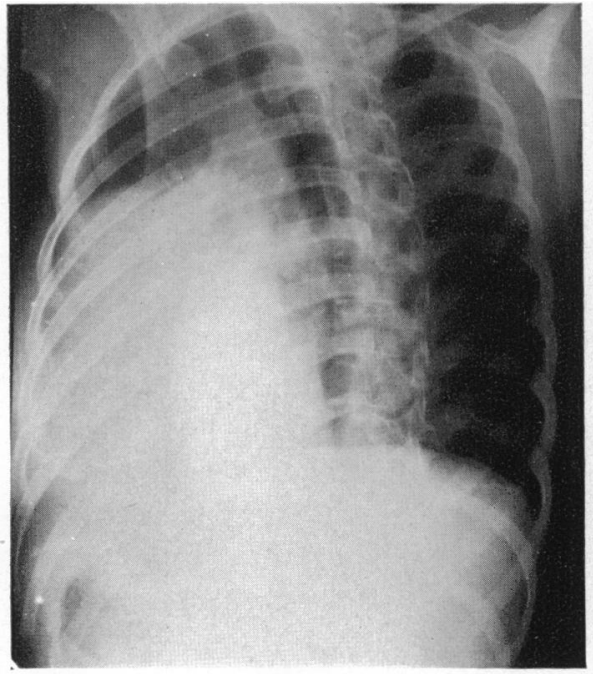

A

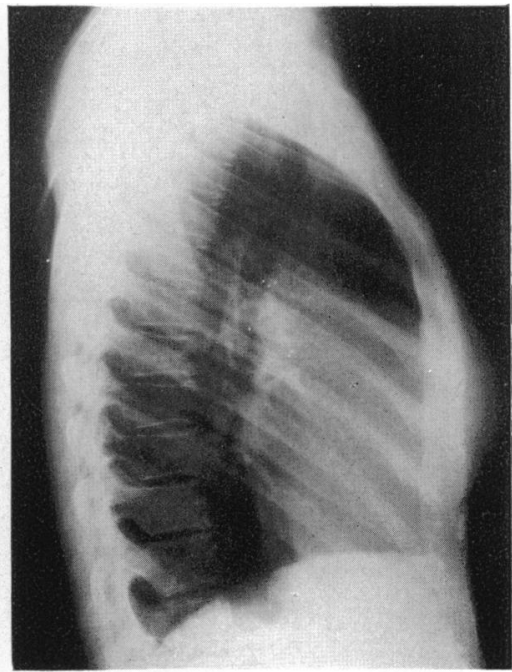

B

FIG. 2.-(A) Radiogram (second oblique position) showing the aneurysm of the ascending aorta.

(B) Lateral view of chest, showing the aneurysm of the ascending aorta pressing on the anterior thoracic wall. 
never satisfactorily secured. The electrocardiographic report, which also was substantially the same on each admission, read as follows: very slight right axis deviation, $\mathrm{P}_{1}$ and $\mathrm{P}_{2}$ slightly high, $\mathrm{P}-\mathrm{R}$ interval nörmal $(0 \cdot 16 \mathrm{sec}$.), Q-T slightly long $(0.40 \mathrm{sec}$.), $\mathrm{S}-\mathrm{T}$ slightly depressed, and $\mathrm{T}$ waves normal (Ashman's formula, 1939).

The patient discharged herself from hospital, but was readmitted later in the same month for treatment of her pelvic condition. She remained in a gynæcological ward for three weeks, the findings being essentially the same as those already recorded.

After a third admission in October for treatment of her rectal stricture, when she only remained in hospital five days, she was admitted for the fourth time in January 1939. She complained of the same stabbing pain in the chest, but it was now more severe. Her hands and feet had been swollen for some days.

The pulse rate was 88 per minute, the respiratory rate 18 , and the blood pressure 130/78. She was dyspnœic, and the skin and mucous membranes were pale. Physical examination was essentially the same as before, except that tenderness in the præcordial area and the fullness in the third interspace were more pronounced. The continuous murmur with systolic accentuation was also more prominent. The liver was enlarged two fingers' breadth below the costal margin. There was no fluid in the abdomen, but there was a slight pitting œdema of the feet and ankles.

As during her first stay in hospital, the patient had slight daily rise of temperature to $99-99 \cdot 5^{\circ} \mathrm{F}$. Pain and dyspnœa continued, and symptomatic relief could be secured only by sedatives at regular intervals. She was unwilling to remain in hospital and was finally permitted to leave, unimproved.

She returned for the last time in March 1939, with all her symptoms and findings markedly exacerbated, and with clear evidence of congestive heart failure. She improved under treatment during the next two months, but developed pulmonary œdema in May and died within a few hours. Radioscopic examination shortly after she entered the hospital in March revealed the supposed aneurysm in the region of the pulmonary artery; at this time the posterior mediastinum was clear.

A post-mortem examination was made by Dr. Bjarne Pearson. Each of the pleural cavities contained 800 c.c. of straw-coloured fluid. The pericardial cavity was obliterated by fibrous adhesions, but it was fairly easy to separate the pericardium from the anterior surface of the heart.

The heart weighed $525 \mathrm{~g}$. and had the following measurements: tricuspid valve, $13.0 \mathrm{~cm}$.; pulmonary valve, $9.0 \mathrm{~cm}$.; mitral valve, $10.0 \mathrm{~cm}$.; aortic valve, $7.2 \mathrm{~cm}$; left ventricle, $2.0 \mathrm{~cm}$.; right ventricle, $1.0 \mathrm{~cm}$; left auricle, $0.6 \mathrm{~cm}$.; right auricle, $0.7 \mathrm{~cm}$. The myocardium was firm and light red. No areas of infarction were seen. The coronary arteries showed no sclerosis and their orifices as well as their branches were normal.

The chief pathological finding was an aneurysm of the aorta, located above the junction of the right and left anterior cusps (Fig. 3). It formed a herniation that protruded into the pulmonary artery (Fig. 4), which in turn protruded into 


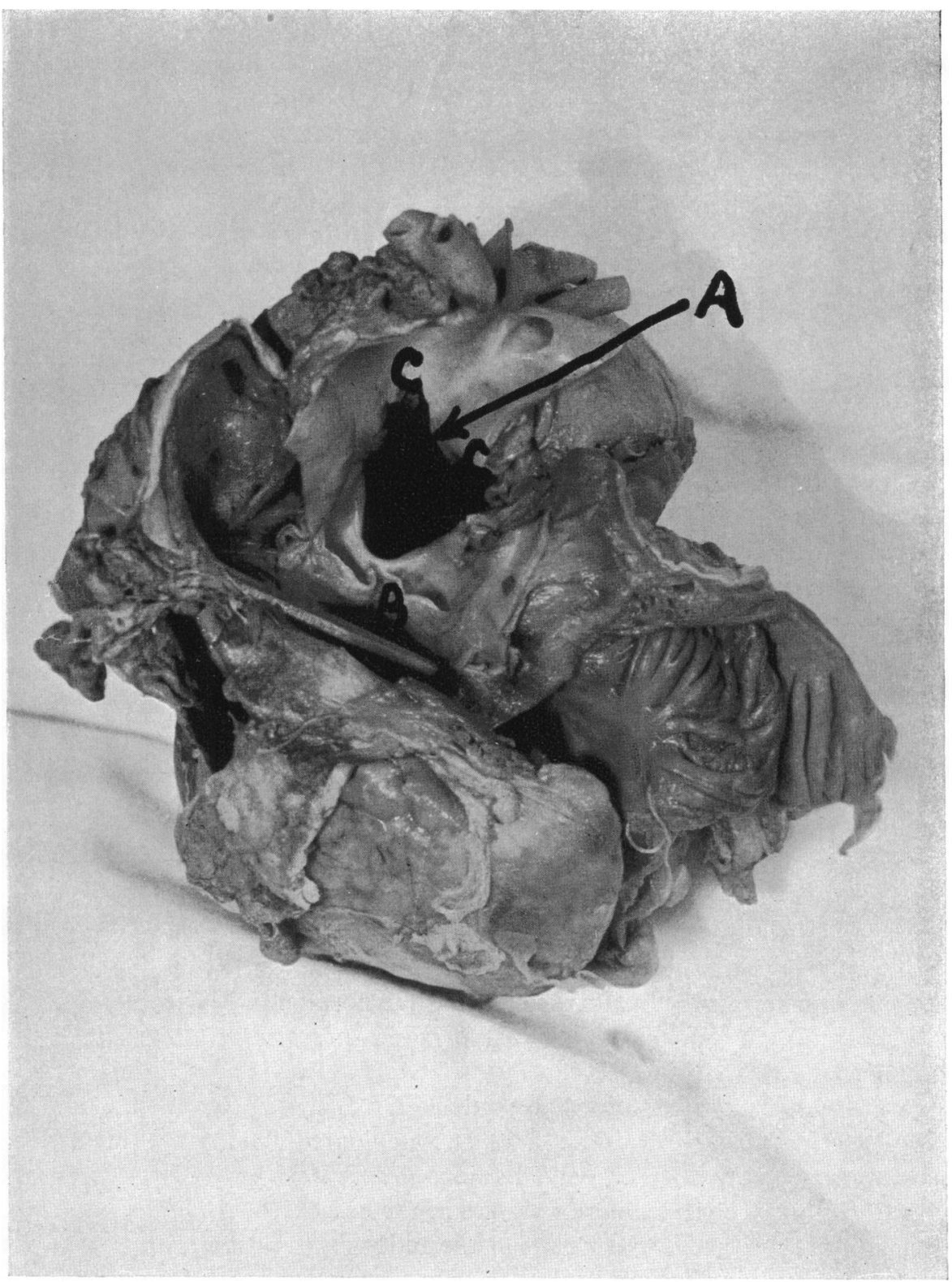

FIG. 3.-Heart, showing the aneurysm of the ascending aorta (A) above the aortic valves (B). The aneurysm extends between the origins of the coronary arteries, which are not well visualized. $\mathbf{C}$ indicates the area in the wall of the aneursym from which sections were taken for microscopic study. 


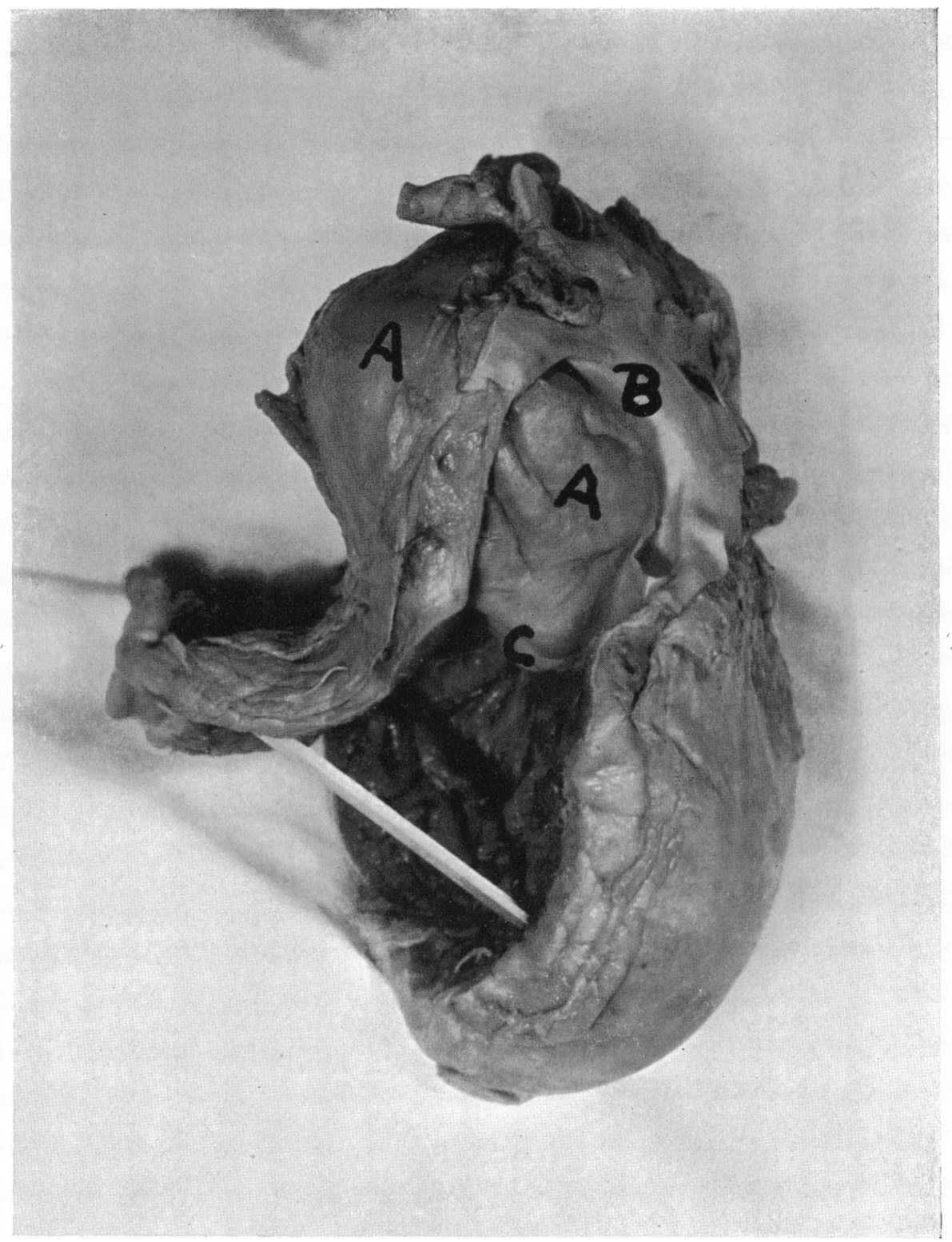

FIG. 4.-Heart, showing aneurysmal sac (A) bulging into the pulmonary artery (B) and obliterating the left posterior cusp $(\mathrm{C})$, thus producing pulmonary stenosis and insufficiency. Note hypertrophy of right ventricle. 
the right ventricle, the combined pressure and anatomical distortion causing stenosis of the pulmonary artery. The aneurysmal sac also distorted the right posterior cusp of the pulmonary valve so that it could not be recognized as such and appeared merely as a thin rim of tissue. Evidence of early pressure changes was seen on the internal surface of the chest overlying the aneurysm, but there was no erosion. The mouth of the aneurysm measured 2.25 by $2 \mathrm{~cm}$., the depth was $5.75 \mathrm{~cm}$., and the transverse and the posterior diameters were both $6.5 \mathrm{~cm}$.

Except for the spleen, which weighed only $60 \mathrm{~g}$., and the pelvic organs and rectum, which revealed the conditions described clinically, the other postmortem findings were unimportant. Microscopic examination revealed syphilitic changes in the aorta.

The diagnosis was aneurysm of the aorta with pulmonary stenosis caused by herniation of the aneurysm into the pulmonary artery.

\section{Comment}

The pertinent literature is not extensive. Aneurysm of the pulmonary artery is rare. Wahl and Gard (1931) found only 70 cases on record up to 1925, including the case they themselves were reporting.

Crawford and de Veer (1932) reported an aortic aneurysm located $1 \mathrm{~cm}$. above the right and left aortic valves, which pressed on the base of the pulmonary artery and conus, as well as on the interventricular septum, and thus produced a right bundle branch block. They cited the similar case reported by Rothschild et al. and the cases reported by Bruffalini and by Stejfa.

Delp and Maxwell (1938) reviewed the papers on rupture of aortic aneurysms into the pulmonary artery and collected 46 cases, including their own. They mentioned that Boyd had reported 18 such ruptures in 592 aortic aneurysms and Stevenson 3, and that single cases had been reported by Kappis, Peacock, Taylor, Kork, and Potter. Kampmeier (1938) found only one rupture into the pulmonary artery in 633 aortic aneurysms, and observed four aneurysms of the sinus of Valsalva in the same material.

As this paper was being prepared for press there appeared the report of Garvin and Siegel (1939) concerning three cases of cor pulmonale due to obstruction of the pulmonary artery by an aneurysm of the aorta. On the basis of their own and other observations they conclude that: if myocardial insufficiency, especially of the right heart, is evident; if radioscopy shows the aneurysm in such a position that it could press on the pulmonary artery; if the electrocardiogram reveals right axis deviation; and if all other causes of heart failure are excluded; then the diagnosis of obstruction of the pulmonary artery by pressure from an aortic aneurysm should be considered probable.

In the case here reported several clinicians were unable to agree upon the diagnosis, and aneurysm of the pulmonary artery, aneurysm of the aorta with rupture into the pulmonary artery, aneurysm of the sinus of Valsalva, and aneurysm of a patent ductus Botalli were variously suggested. The first was 
considered the most probable, though the combination of an aneurysm of the pulmonary artery with a patent ductus Botalli was discussed as a possibility. The radiologists argued for an aneurysm of the pulmonary artery, because the films revealed a normal aortic knob with the main shadow overlying the region of the pulmonary artery (Figs. 1-2), and radioscopy shortly before death revealed a clear posterior mediastinum, which seemed to indicate that the aneurysm pointed forward in the region of the pulmonary artery. Wahl and Gard's views of pulmonary aneurysms are comparable with the views taken of this particular case.

Since the patient had previously been in fairly good health and had had no symptoms until her twenty-eighth year, the diagnosis of congenital heart disease as manifested by a patent ductus Botalli seemed somewhat unreasonable, particularly as the first complaint referable to the cardiovascular system was moderate dyspnœa, with stabbing pain in the præcordium. The continuous murmur heard over the chest, combined with the radiological findings, made the diagnosis of aneurysm almost a foregone conclusion. The præcordial pain as well as the extreme tenderness over the third left interspace favoured some involvement of the pulmonary artery. There was no evidence of mitral disease and the slight right axis deviation was considered due to some disease in the pulmonary artery itself. On the other hand, there was no doubt of the existence of an old syphilitic infection, as proved by repeated positive Wassermann reactions, and syphilis of the pulmonary artery is extremely rare. It was therefore felt that if the aneurysm did involve this artery, some cause other than syphilis must be responsible.

At autopsy these conflicting findings were made clear when the lesion was revealed to be an aneurysm of the aorta located immediately above the sinus of Valsalva and directed forward and slightly to the left. It pressed upon the base of the pulmonary artery and thus obliterated the posterior cusp and produced pulmonary stenosis and insufficiency.

Of the several reports on record concerning rupture of an aortic aneurysm into the pulmonary artery, the case reported by Crawford and deVeer (1932) resembles the case herewith reported so far as location is concerned. In this instance, however, rupture did not occur and the clinical picture simulated that of pulmonary aneurysm.

\section{Summary}

A case is reported in which an aneurysm of the aorta was so located as to produce pulmonary stenosis and insufficiency, and a clinical picture suggestive of aneurysm of the pulmonary artery. Previous reports are briefly reviewed, and it is pointed out that the location of the aneurysm in the reported case is very unusual, as are its ultimate effects upon the pulmonary system. 


\section{REFERENCES}

Ashman, R. (1939). Proc. Soc. exper. Biol. \& Med., 40, 150.

Crawford, J. H., and deVeer, J. A. (1932). Amer. Heart J., 7, 780.

Delp, M. H., and Maxwell, R. (1938). J. Amer. med. Ass., 110, 1647.

Garvin, C. F., and Siegel, M. L. (1939). Amer. J. med. Sci., 198, 679.

Kampmeier, R. H. (1938). Ann. intern. Med., 12, 624.

Wahl, H. R., and Gard, R. L. (1931). Surg. Gynec. \& Obst., 52, 1129. 